\title{
Attachment and College Academic Success: A Four-Year Longitudinal Study
}

\author{
Robert M. Kurland, Harold I. Siegel \\ Rutgers University-Newark, Newark, USA \\ Email: rmkurland@gmail.com, hisiegel@psychology.rutgers.edu
}

How to cite this paper: Kurland, R. M., \& Siegel, H. I. (2020). Attachment and College Academic Success: A Four-Year Longitudinal Study. Open Journal of Social Sciences, 8, 45-55.

https://doi.org/10.4236/jss.2020.812005

Received: June 5, 2020

Accepted: December 6, 2020

Published: December 9, 2020

Copyright $\odot 2020$ by author(s) and Scientific Research Publishing Inc. This work is licensed under the Creative Commons Attribution International License (CC BY 4.0).

http://creativecommons.org/licenses/by/4.0/

(c) (i) Open Access

\begin{abstract}
This longitudinal study examined the influence of attachment security on student academic success over their first four years in college. Eighty-five first-semester students provided their attachment dimensions and psychological indices at the beginning of their college careers. Students' academic records were accessed throughout the four-year period. Securely attached students maintained higher GPA's and graduated at a higher rate than insecurely attached students. Regression analysis analyzed the influence of attachment security on four-year cumulative college GPA from high school to college while controlling for high school GPA. The results indicate that attachment security had a significant effect on students' four-year cumulative GPA.
\end{abstract}

\section{Keywords}

Attachment, College, Academic Success, Retention, Graduation Rates, GPA

\section{Attachment and College Academic Success: A Four-Year Longitudinal Study}

Higher Education professionals are constantly trying to find ways to improve student retention and successful progress towards degree completion. While many psychological factors have been considered (Saunders-Scott, Braley, \& Stennes-Spidahl, 2017), very few have examined the influence of Attachment Theory over a 4-year time period. Previous research (Kurland \& Siegel, 2013) showed that attachment is related to academic success during the transition from high school to college. The current study examined academic success longitudinally over four years in college students. In discussing academic achievement and attachment, much of the research measured general levels of attachment (i.e., high, low, etc.). This research showed that students who are highly 
attached to their parents (Kenny, 1990), peers (Fass \& Tubman, 2002), and professors (Eccles et al., 1993) demonstrate higher academic achievement. While level of attachment is important, security or insecurity of attachment needs to be studied as well. As attachment security remains fairly consistent through one's lifespan (Baldwin \& Fehr, 1995), it is important to look at the effects of attachment on academic related achievement through different developmental periods.

\subsection{Childhood}

As children grow, they encounter increasingly difficult challenges (academic and non-academic). Children who are classified as secure generally are more comfortable exploring the world with the confidence that they will have their parent or parents (secure base) there for them (Mikulincer \& Shaver, 2007). As children progress through the educational system, they tend to become more independent (Piaget \& Inhelder, 1969) as they advance academically. Simultaneously, there is a general feeling that as children grow and become more independent, the need for a teacher's perceived support tends to decrease (Harter, 1996).

Attachment styles affect early exposure to and achievement in preschool and grammar school. Matas, Arend, \& Sroufe (1978) found that securely attached children at the age of 18 months were "more enthusiastic, persistent, cooperative, and, in general, more effective than insecurely attached infants" (p. 1). These qualities prepare them for the challenge of academic rigors. Bus \& Van IJzendoorn (1988) studied children aged $1 \frac{1}{2}$ through $5 \frac{1}{2}$ years. They found that securely attached children paid more attention to readings than anxiously attached children. In looking at seven-year-olds, Jacobsen, Edelstein, \& Hofmann (1994) found securely attached children had better cognitive abilities later in life than insecurely classified children. Additionally, these securely attached children demonstrated better deductive reasoning. Moss \& St-Laurent (2001) found similar results in a three-year longitudinal study. After analyzing children's attachment styles through a separation-reunion procedure at age six, Moss and St. Laurant later analyzed children's academic motivation and achievement at age eight. While they found that there was no specific relation between attachment style and IQ, they did find a positive relationship between academic achievement and secure attachment to the child's mother.

There have also been a number of studies looking specifically at insecure styles and negative effects on academic achievement. Matas et al. (1978) found that avoidant and ambivalent toddlers explored less and thus were less involved in school and academic-related tasks and activities. Cassidy \& Berlin (1994) also found that ambivalent children were more concerned with focusing on the teacher's physical proximity and attachment availability than they were on academic tasks and activities. These differing qualities between secure and insecure individuals may directly relate to the ability of securely attached children to obtain higher grades throughout school. 


\subsection{Adolescence}

Similar research supports these previous findings at the high school level. Among early adolescents, there is a relationship between the students' academic motivation and achievement based upon positive (or secure) attachment to their parents and teachers (Duchesne \& Larose, 2007). Additionally, Wong, Wiest, \& Cusick (2002) found comparable results in terms of academic achievement in ninth graders. Although there was a decrease in the amount of interaction with the parents, students who established secure relationships tended to prefer academic challenges (with an increased motivation to achieve) and were found to be more competent in math and reading skills.

Other studies examined the relationship between student and teacher. Learner \& Kruger (1997) found a positive relationship between a student's attachment to his or her teacher and academic success. These findings coincide with the theory that attachment can additionally be formed with other individuals who are not primary care givers (Ainsworth, 1989). Furthermore, these findings revealed that parental attachment (family) and attachment to a teacher (non-family) were both individually and collectively related to academic motivation and that academic self-concept had a significant effect on academic motivation. Hence, individuals may experience a shift in regard to the impact of attachment figures as teachers play a more significant role in a student's academic motivation and success.

\subsection{College Years}

Larose, Bernier, \& Tarabulsy (2005) studied academic performance during the transition between high school and college. They studied 62 students' academic records in high school and then again after each of their first three semesters in college. Secure students showed better learning abilities compared with dismissive and preoccupied students. They also discovered that dismissive students performed at the lowest levels. Larose et al. theorized that this association was mediated by changes in the quality of attention during the transition. As dismissive students are less anxious, but more avoidant, they may feel that while they themselves remain consistent, being exposed to a new environment may bring about additional interactions that they are unsure (and untrusting) of and, thus they attempt to avoid interactions at a critical time when more interactions and support are needed to better succeed.

Fass \& Tubman (2002) studied the influence of parental and peer attachment on the academic achievement of 357 undergraduate students who were attending a four-year urban university in the southeast. They used the Inventory of Parental and Peer Attachment (IPPA; Armsden \& Greenburg, 1987) to measure attachment levels to both parents and peers. The IPPA examines levels of trust, communication, and alienation; more specifically, high levels of trust and communication (and low levels of alienation) can directly be related to avoidant attachment styles' model of positive view of self and negative view of others. In 
order to obtain information on the students' academic performance in high school and college, the researchers utilized another self-report survey, the Student Academic Profile. Fass and Tubman found that students' perceived level of attachment (high, medium, and low) to their parents and their peers had significant effects on their self-reported academic performance. Students who had low attachment to both parents and peers had significantly lower GPA's than those that scored high with both parents and peers. Accordingly, those with attachment styles low in avoidance had self-reported high academic performance. While parental and peer attachment were significant factors, they were certainly not the only factors to influence GPA. Unfortunately, the results were not fully discussed in regard to groups who may have scored high with one and low with the other (parents and peers).

Cutrona, Cole, Colangelo, Assouline, \& Russell (1994) studied 131 undergraduate students enrolled in an introductory psychology course. They used a self-report method to assess perceived social support. Additionally, as opposed to Fass and Tubman's self-report method, they obtained their subjects' actual GPA's from the university registrar to ensure accuracy and prevent self-reporting bias. They did not find a significant direct correlation between secure parental attachment and GPA. However, they predicted and found that secure attachment would lead to lower anxiety, a hypothesis consistent with Attachment Theory, and that lower anxiety would lead to higher academic self-efficacy, which in turn would ultimately lead to higher GPA's. Interestingly, while Fass and Tubman may have found a relationship with level of attachment and academic success, Cutrona et al. (1994) found that only parent support and attachment, as opposed to friends and romantic partners, significantly predicted grade point average.

The purpose of the current study was to expand upon previous findings which have shown a relationship between attachment and student academic success during the transition from high school to college. In this study students' academic progress was followed throughout their first four years of college. Specific data derived from university records included term and cumulative grade point average (GPA), credits attempted and completed, student retention, and graduation rates. It was hypothesized that attachment would have an influence on college students' academic success as they continue through their college experience.

\section{Method}

\subsection{Participants}

The study was conducted using 85 incoming first-year college students. There were 21 males $(24.7 \%)$ and 64 females $(75.3 \%)$. The average age was 18.26 ( $\mathrm{SD}=.99)$. In terms of ethnicity, 22 participants self-reported as Hispanic (25.9\%), 18 Caucasian (21.2\%), 20 Asian (23.5\%), 8 African-American (9.4\%), 7 Asian-Pacific Rim (8.2\%), 4 Middle Eastern (4.7\%), and 6 classified 
themselves as other (7.1\%).

\subsection{Materials}

The participants completed the following surveys online: demographic questions, the Relationship Structure (RS) questionnaire (Fraley, Niedenthal, Marks, Brumbaugh, \& Vicary, 2006) which is used to measure avoidance and anxiety of attachment, and the four-paragraph relationship questionnaire (Bartholomew \& Horowitz, 1991). Additionally, participants were asked to give permission to the experimenter to allow access to their academic records (including GPA, credits attempted/earned, choice of major, high school GPA, and SAT scores).

\subsection{Procedure}

E-mails were sent to approximately 800 incoming freshmen who had registered university e-mail addresses inviting them to participate in the survey. Each participant was asked to complete each questionnaire in the survey. The entire survey took approximately 30 minutes to complete. These students' academic records were reviewed over four years of enrollment at the college.

\subsection{Statistical Analysis}

For this study, $t$-tests, crosstabs analysis, and correlational analyses were used to determine significant differences $(p<.05)$ between various aspects of student success as it relates to attachment security/insecurity and avoidance/anxiety. In addition, regression analysis was used to examine the effect of attachment on academic success across the four years.

\section{Results}

One major limitation of this study involves the sample size and return rate. Approximately 800 students were invited to participate, and with only 85 responding, the return rate is approximately $10.5 \%$. Therefore, a further examination of the 800 students was performed showing that the sample closely represents the population in terms of demographic information (see Table 1). The only demographic information that may not be representative is gender as the population showed that males account for $45 \%$ and females account for $55 \%$. However, research in attachment has shown that gender is not a good predictor of attachment styles (Mikulincer \& Shaver, 2007).

Using a categorical measurement of attachment styles, the results indicated a strong relationship between attachment and college student academic success. In terms of GPA, secure students maintained an average GPA of 3.295 compared to the $2.999 \mathrm{GPA}$ of insecure students (which include dismissive, preoccupied, and fearful) $[t(1,58)=2.124, p=.038]$ over eight semesters (Figure 1 ).

While retention at the end of the four years was not significant, over the course of the first two years (see Figure 2), as these students entered their junior year, secure students were retained at a rate of $96.88 \%$ compared to an insecure retention rate of $81.40 \%\left[X^{2}(1, \mathrm{~N}=75)=4.163, p=.041\right]$. 
Table 1. Demographic comparison of sample and populations.

\begin{tabular}{lcc}
\hline & Population & Sample \\
\hline Age & 18.1 & 18.26 \\
Gender & & \\
$\quad$ Male & $45 \%$ & $25 \%$ \\
$\quad$ Female & $55 \%$ & $75 \%$ \\
Ethnicity & & \\
African-American & $18.8 \%$ & $9.4 \%$ \\
Asian & $25 \%$ & $31.7 \%$ \\
$\quad$ Latino(a) & $18.9 \%$ & $25.9 \%$ \\
$\quad$ White/Caucasian & $28.2 \%$ & $21.2 \%$ \\
Other & $9.1 \%$ & $11.8 \%$ \\
\hline
\end{tabular}

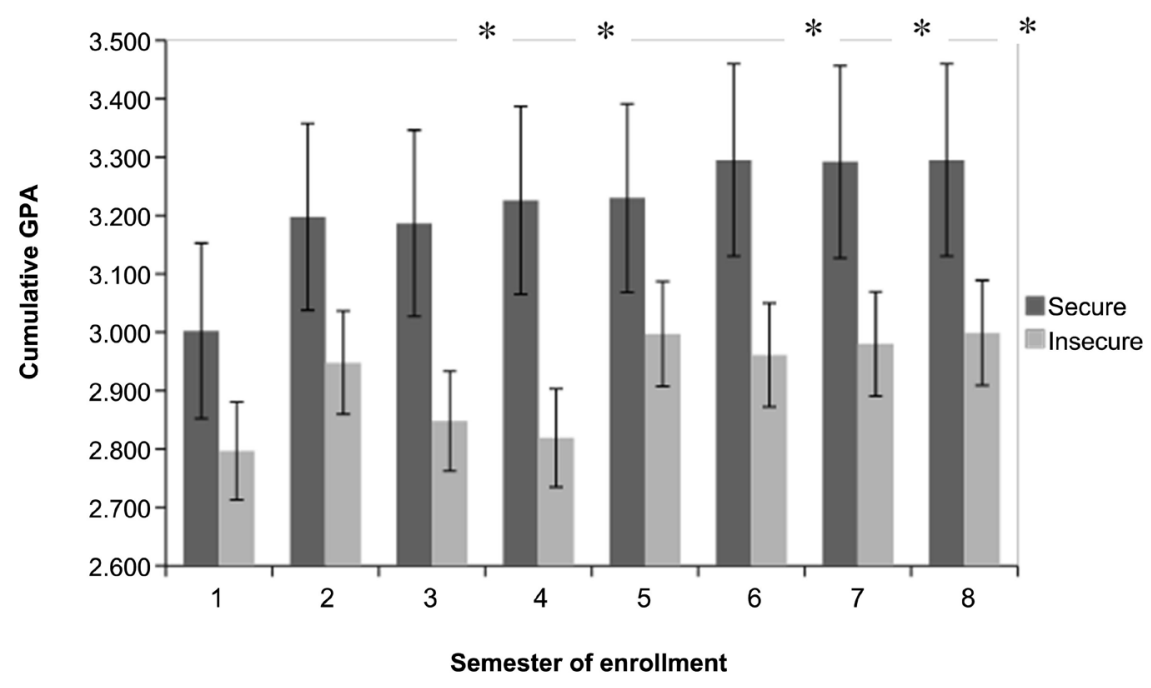

Figure 1. Attachment security and cumulative GPA over four-year span.

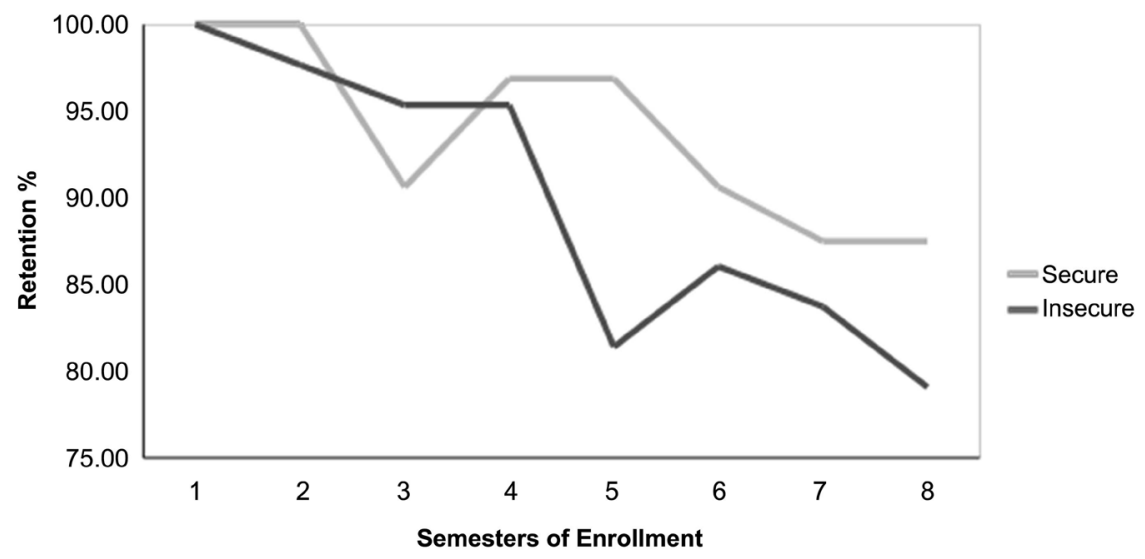

Figure 2. Attachment security and 4-year retention rate.

During the four-year period, the secure students' graduation rate was $43.75 \%$ compared to an insecure graduation rate of $27.91 \%\left[X^{2}(1, \mathrm{~N}=75)=3.961, p\right.$ 
$=.047]$. See Figure 3 .

To further examine the influence of attachment, a regression analysis was used to examine the influence of attachment security on four-year cumulative college GPA from high school to college while controlling for high school GPA (see Table 2). The results indicated that attachment security had a significant effect on students' four-year cumulative GPA $(\beta=.258, p=.049)$. This model accounts for $17.9 \%$ of the variance. See Figure 4.

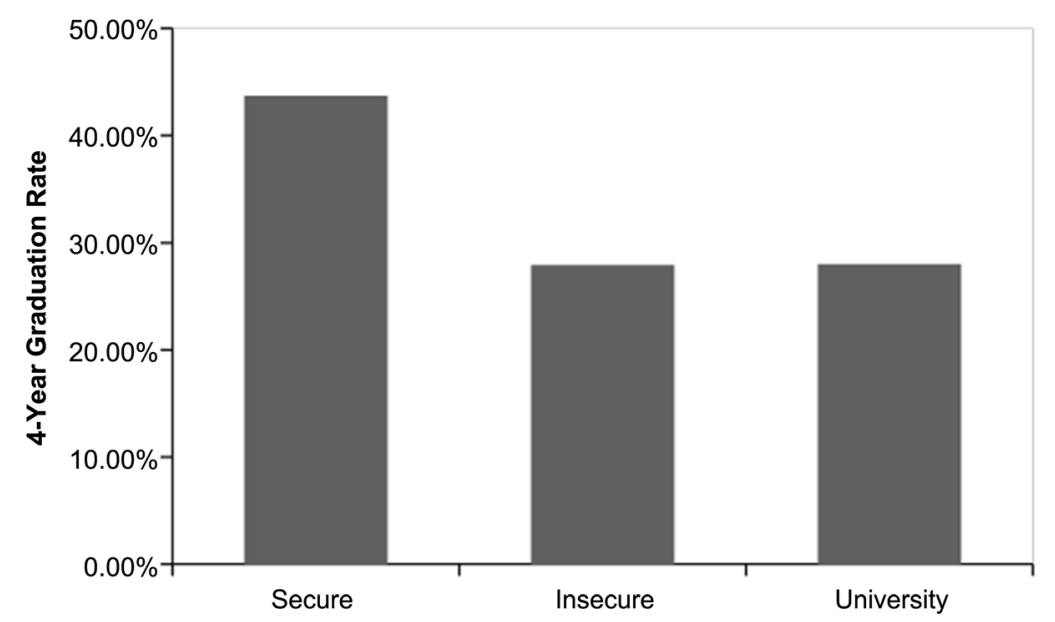

Figure 3. Attachment security and four-year graduation rates. For anonymity sake, the name of the university has been removed.

Table 2. Regression results for influence of attachment and HS GPA on cumulative GPA.

\begin{tabular}{ccccc}
\hline & $\mathrm{b}$ & $\mathrm{SE}$ & $\beta$ & sig \\
\hline Attachment security & .258 & .130 & .237 & .049 \\
High School GPA & .392 & .121 & .390 & .002 \\
\hline
\end{tabular}

Notes: $R^{2}=.208$.

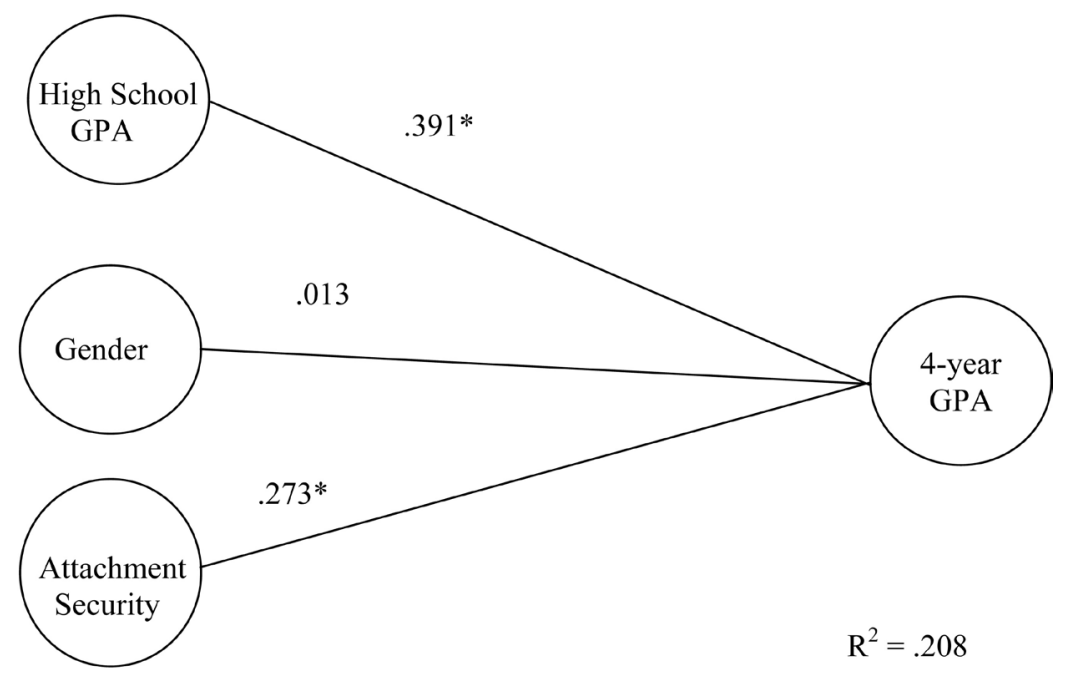

Figure 4. Regression results for the influence of attachment and high school GPA on cumulative GPA. 


\section{Discussion}

The findings support and extend the general hypothesis that attachment security has a positive influence on college student success. Secure students achieved higher GPA's compared to those of insecure students, and many of the insecure students who were no longer retained had lower average GPAs (prior to dropping out) compared to the insecure students who were still enrolled. Therefore, if retention was not a factor, then this difference would be greater.

The graduation rate may be one of the most significant measures of student success. If a student does not graduate, then GPA, credits, time to graduation, etc. are all inconsequential. There was a significant difference in the graduation rate of secure students versus insecure students. In fact, according to the university's Office of Institutional Research (n.d.), 28\% of students finish their degrees within four years and 59\% within six years. This shows that most of the insecure population is closer to that average graduation rate at the university, and that the secure population is well above that number.

Insecure anxiously attached individuals tend to feel concerned about their attachment relationships and are defined as having a negative view of self (Fraley, Waller, \& Brennan, 2000). Insecure anxious students struggle with close relationships and use these relationships as a source of approval. This focus on relationships places the social needs of the individual as a priority over many endeavors including academics. Using attachment theory, it may be possible to speculate on how these students behave at the college level. They may attend classes and look forward to the interactive aspects of being within the classroom; however, they may lose focus on their academic needs and requirements. These students may not spend enough time studying on their own, preferring to study with groups. However, even in group study, they may be too focused on seeking approval from their fellow students that even the academic purpose of study groups becomes lost. This focus on relationships may cause students to concentrate less on their academic pursuits leading them ultimately being academically dismissed from the university. Poor retention may also be a result of the inherent aspects of their attachment needs as they may also find that they are unable to fulfill their attachment needs and thus leave the university to either return home to their previous support groups and attachment figures, or to attend another college in hopes that their attachment needs can be met elsewhere. The insecure anxious students who tend to take fewer credits or unsuccessfully pass more classes per semester will take longer to graduate, thus influencing graduation rates. Insecure anxious students may also be looking ahead with concern about making another life transition. They may be apprehensive about having to fully transition into adulthood and form new relationships and thus be delaying their inevitable next step (Bucx \& Van Wel, 2008).

Avoidant insecure individuals dismiss the value of close relationships and have a negative view of others (Fraley, Waller, \& Brennan, 2000). These types of students are less likely to socialize with other students and may avoid interac- 
tions with university officials (e.g., instructors, advisors, tutors) who would best be able to provide them with support. Without academic (or non-academic) support and guidance, these students may be more likely to struggle with their academics resulting in lower GPAs. In terms of retention, avoidant students who struggle with forming closer relationships are less likely to feel connected to their college and thus may be more willing to leave. Retention is another factor that directly influences graduation rates. Students who are avoidant may see the end of college as a final step into the real world where they are expected to start a career, form new bonds, and further engage with relationship building that they may not be ready to face. They may see staying in college as a means for delaying this next step/transition, causing them to delay graduation. Avoidant students may also have been taking fewer credits per semester (which means slower progress towards graduation) as a means of avoiding social interactions within the classroom.

\section{Implications and Future Research}

The results of this paper can be used to add to previously published research on student success. It is the hope of the authors that colleges and universities will be able to factor in the impact of different attachment styles when rethinking student academic advisement, student affairs, and the development of academic and non-academic program development. By better understanding these characteristics, can we better create these programs and services. Further research should be conducted to look at specific variables (i.e. psychological, behavioral, cognitive) that may affect this relationship between attachment and academic success.

\section{Conflicts of Interest}

The authors declare no conflicts of interest regarding the publication of this paper.

\section{References}

Ainsworth, M. D. S. (1989). Attachments beyond Infancy. American Psychologist, 44, 709-716. https://doi.org/10.1037/0003-066X.44.4.709

Armsden, G. C., \& Greenberg, M. T. (1987). The Inventory of Parent and Peer Attachment: Individual Differences and Their Relationship to Psychological Well-Being in Adolescence. Journal of Youth and Adolescence, 16, 427-454. https://doi.org/10.1007/BF02202939

Baldwin, M. W., \& Fehr, B. (1995). On the Instability of Attachment Style Ratings. Personal Relationships, 2, 247-261. https://doi.org/10.1111/j.1475-6811.1995.tb00090.x

Bartholomew, K., \& Horowitz, L. M. (1991). Attachment Styles among Young Adults: A Test of a Four-Category Model. Journal of Personality and Social Psychology, 61, 226-244. https://doi.org/10.1037/0022-3514.61.2.226

Bucx, F., \& Van Wel, F. (2008). Parental Bond and Life Course Transitions from Adolescence to Young Adulthood. Adolescence, 43, 71-88. 
Bus, A. G., \& Van IJzendoorn, M. H. (1988). Mother-Child Interaction, Attachment, and Emergent Literacy: A Cross-Sectional Study. Child Development, 59, 1262-1272. https://doi.org/10.2307/1130489

Cassidy, J., \& Berlin, L. J. (1994). The Insecure/Ambivalent Pattern of Attachment: Theory and Research. Child Development, 65, 971-991. https://doi.org/10.2307/1131298

Cutrona, C., Cole, V., Colangelo, N., Assouline, S., \& Russell, D. (1994). Perceived Parental Social Support and Academic Achievement: An Attachment Theory Perspective. Journal of Personality and Social Psychology, 66, 369-378. https://doi.org/10.1037/0022-3514.66.2.369

Duchesne, S., \& Larose, S. (2007). Adolescent Parental Attachment and Academic Motivation and Performance in Early Adolescence. Journal of Applied Social Psychology, 37, 1501-1521. https://doi.org/10.1111/j.1559-1816.2007.00224.x

Eccles, J. S., Midgley, C., Wigfield, A., Buchanan, C. M., Reuman, D., Flanagan, C., \& Maclver, D. (1993). Development during Adolescence: The Impact of Stage-Environment Fit on Young Adolescents' Experiences in Schools and Families. American Psychologist, 48, 90-101. https://doi.org/10.1037/0003-066X.48.2.90

Fass, M., \& Tubman, J. (2002). The Influence of Parental and Peer Attachment on College Students' Academic Achievement. Psychology in the Schools, 39, 561-573. https://doi.org/10.1002/pits.10050

Fraley, R. C., Waller, N. G., \& Brennan, K. A. (2000). An Item-Response Theory Analysis of Self-Report Measures of Adult Attachment. Journal of Personality and Social Psychology, 78, 350-365. https://doi.org/10.1037/0022-3514.78.2.350

Fraley, R., Niedenthal, P., Marks, M., Brumbaugh, C., \& Vicary, A. (2006). Adult Attachment and the Perception of Emotional Expressions: Probing the Hyperactivating Strategies Underlying Anxious Attachment. Journal of Personality, 74, 1163-1190. https://doi.org/10.1111/j.1467-6494.2006.00406.x

Harter, S. (1996). Teacher and Classmate Influences on Scholastic Motivation, Self-Esteem, and Level of Voice in Adolescents. Social Motivation: Understanding Children's School Adjustment. Cambridge: Cambridge University Press. https://doi.org/10.1017/CBO9780511571190.004

Jacobsen, T., Edelstein, W., \& Hofmann, V. (1994). A Longitudinal Study of the Relation between Attachment Representations in Childhood and Cognitive Functioning in Childhood and Adolescence. Developmental Psychology, 30, 112-124. https://doi.org/10.1037/0012-1649.30.1.112

Kenny, M. E. (1990). College Seniors' Perceptions of Parental Attachments: The Value and Stability of Family Ties. Journal of College Student Development, 31, 39-46.

Kurland, R. M., \& Siegel, H. I. (2013). Attachment and Student Success during the Transition to College. ACADA Journal, 33, 16-28. https://doi.org/10.12930/NACADA-12-252

Larose, S., Bernier, A., \& Tarabulsy, G. M. (2005). Attachment State of Mind, Learning Dispositions, and Academic Performance during the College Transition. Developmental Psychology, 41, 281-289. https://doi.org/10.1037/0012-1649.41.1.281

Learner, D., \& Kruger, L. (1997). Attachment, Self-Concept, and Academic Motivation in High-School Students. American Journal of Orthopsychiatry, 67, 485-492. https://doi.org/10.1037/h0080249

Matas, L., Arend, R. A., \& Sroufe, L. A. (1978). Continuity of Adaptation in the Second Year: The Relationship between Quality of Attachment and Later Competence. Child Development, 49, 547-556. https://doi.org/10.2307/1128221 
Mikulincer, M., \& Shaver, P. (2007). Attachment in Adulthood. New York: The Guilford Press.

Moss, E., \& St-Laurent, D. (2001). Attachment at School Age and Academic Performance. Developmental Psychology, 37, 863-874. https://doi.org/10.1037/0012-1649.37.6.863

Piaget, J., \& Inhelder, B. (1969). The Psychology of the Child. New York: Basic Books.

Saunders-Scott, D., Brsaley, M. B., \& Stenned-Spidahl, N. (2017). Traditional and Psychological Factors Associated with Academic Success: Investigating Best Predictors of College Retention. Motivation and Emotion, 42, 459-465. https://doi.org/10.1007/s11031-017-9660-4

Wong, E., Wiest, D., \& Cusick, L. (2002). Perceptions of Autonomy Support, Parent Attachment, Competence and Self-Worth as Predictors of Motivational Orientation and Academic Achievement: An Examination of Sixth- and Ninth-Grade Regular Education Students. Adolescence, 37, 255-266. 